P20 A DATABASE APPROACH TO DOSE SCORE CALCULATION AS A TOOL TO IDENTIFY 'AT RISK' CHRONIC OBSTRUCTIVE PULMONARY DISEASE PATIENTS THROUGH CLINICAL RECORDS

${ }^{1}$ LA Rigge, ${ }^{2} \mathrm{M}$ Johnson, ${ }^{2} \mathrm{D}$ Culliford, ${ }^{3} \mathrm{~N}$ Williams, ${ }^{4} \mathrm{~L}$ Josephs, ${ }^{4} \mathrm{M}$ Thomas, ${ }^{1} \mathrm{~T}$ Wilkinson. ${ }^{1}$ NIHR CLAHRC Wessex, University of Southampton, Clinical and Experimental Sciences \& University Hospital Southampton NHS Foundation Trust, Southampton, UK; ${ }^{2}$ NIHR CLAHRC Wessex, Methodological Hub, Southampton, UK; ${ }^{3}$ University of Southampton, Clinical and Experimental Sciences \& University Hospital Southampton NHS Foundation Trust, Southampton, UK; ${ }^{4}$ NIHR CLAHRC Wessex, University of Southampton, Primary Care and Population Sciences, Southampton, UK

\subsection{6/thoraxjnl-2015-207770.157}

Establishing how best to target resources remains a challenge within COPD as this is a heterogeneous patient group with complex needs often poorly reflected by routinely collected clinical measurements such as $\mathrm{FEV}_{1}$.

Jones et al. created The DOSE score (dyspnoea (MRC score), obstruction $\left(\mathrm{FEV}_{1}\right.$ percentage predicted), smoking status and exacerbation number in a year) (Table 1) a validated, clinically useful measure of risk stratification in COPD which utilises data already routinely collected in Primary Care for QOF review.

Abstract P20 Table 1 DOSE INDEX SCORING SYSTEM (Jones et al. AJRCCM 2009;180(12):1189-95): The DOSE Index points associated with every category of all four variables are added to build the DOSE Index score

\begin{tabular}{|l|cccc|}
\hline \multicolumn{5}{|c|}{ DCSE Index Points } \\
\hline & 0 & 1 & 2 & 3 \\
\cline { 2 - 5 } & $0-1$ & 2 & 3 & 4 \\
MRC Dyspnoea Scale Score & $>50$ & $30-49$ & $<30$ & \\
Smoking status & Non smoker & Smoker & & \\
Exacerbations per year & $0-1$ & $2-3$ & $>3$ & \\
\hline
\end{tabular}

By using a collaborative approach with informatics, statistical and clinical input we developed a database approach to calculating a DOSE score using routinely collected and coded Primary and Secondary Care data. A local NHS database holding anonymised clinical records for over one million patients was used to identify a cohort of over 13,000 patients with codes diagnostic of COPD.

Microsoft Structured Query Language Server was used to identify, cleanse and standardise the required clinical information and calculate the DOSE score, creating a series of functions that can be replicated across other database management systems.

Date of $\mathrm{FEV}_{1}$ percentage predicted was taken as the index date for DOSE score calculation. Where only $\mathrm{FEV}_{1}$ was recorded, a percentage of predicted $\mathrm{FEV}_{1}$ was calculated using available height and age data.

Read codes (the routine coding system used in primary care) and ICD-10 codes were used to compile lists identifying those symptoms, diagnoses and prescriptions indicative of COPD exacerbations. These lists were applied in the year prior to the chosen $\mathrm{FEV}_{1}$ value and, functions were written to cluster those events felt to be reflective of a single exacerbation.

Read codes reflecting MRC score and smoking status closest in time to the index $\mathrm{FEV}_{1}$ measurement were combined with the above measurements, generating a complete score in approximately 10,000 patients. Partial scores were created for a further 1500 patients with incomplete data for the individual score components.
This approach provides a simple way for clinicians to risk stratify their COPD population without increasing their clinical workload. This gives an opportunity to identify those at highest risk of hospital admission and death and proactively allocate resources accordingly.

\section{P21 THE APPLICABILITY OF CURRENT CARDIOVASCULAR RISK SCORES AND CARDIOVASCULAR SURROGATES IN CHRONIC OBSTRUCTIVE PULMONARY DISEASE: A CASE- CONTROL STUDY}

${ }^{1}$ IS Stone, ${ }^{2} \mathrm{MJ}$ Khanji, ${ }^{1} \mathrm{~W}-\mathrm{Y}$ James, ${ }^{2} \mathrm{~A}$ Balawon, ${ }^{2} \mathrm{R}$ Boubertakh, 'L John, ${ }^{3} \mathrm{NC}$ Barnes, ${ }^{2}$ SE Petersen. ${ }^{1}$ Department of Respiratory Medicine, Barts and the London School of Medicine and Dentistry, Queen Mary University of London, London, UK; ${ }^{2}$ NIHR Cardiovascular Biomedical Research Unit, William Harvey Research Institute, Queen Mary University of London, London, UK; ${ }^{3}$ Global Respiratory Franchise, GlaxoSmithKline, Stockley Park, London, United Kngdom

\subsection{6/thoraxjnl-2015-207770.158}

Background COPD is a complex multi-morbid disorder with significant cardiac mortality. Despite this, current cardiovascular scoring systems do not include COPD in their risk prediction models. The aims of this study were to assess whether differences in cardiovascular surrogate markers exist in COPD and to further our understanding of the relationship of COPD to cardiovascular structure and function.

Methods This post-hoc cross-sectional analysis utilised baseline data from two randomised controlled trials ( $\mathrm{n}=36$ and 54). 26 COPD patients were matched for global cardiovascular risk with 26 controls with normal lung function using QRISK2, a validated scoring system for predicting the 10 -year risk of cardiovascular disease in a United Kingdom population. Patients underwent cardiac magnetic resonance imaging, arterial stiffness and lung function measurements.

Results Pulse wave velocity (PWV) (mean difference $+1.0 \mathrm{~m} / \mathrm{s}$, 95\% CI $0.02-1.92 ; \mathrm{p}=0.045)$ and total arterial compliance (TAC) (mean difference $-0.27 \mathrm{~mL} / \mathrm{m}^{2} / \mathrm{mmHg}$, 95\% CI -0.39 , $0.15 ; \mathrm{p}<0.001)$ were adversely affected in COPD compared to the control group matched for cardiovascular risk. In the whole cohort $(\mathrm{n}=90)$ QRISK2 $(\beta=0.046, \mathrm{p}=0.017)$ and FEV1 $(\beta$ $=-0.013, \mathrm{p}=0.022$ ) were associated with PWV in multivariate analysis. The relationship between QRISK2 and PWV appeared to be modified by COPD, where the interaction term reached borderline significance $(\mathrm{p}=0.060)$. FEV1 $(\beta=0.005, \mathrm{p}=$ 0.004 ) was also associated with TAC in multivariate analysis. Cardiac chamber size and stroke volume was decreased in COPD compared to controls. The mean difference in left ventricle stroke volume index (LVSVI) and left and right end diastolic volume index was $-10.3 \mathrm{ml} / \mathrm{m}^{2}$ (95\% CI $-15.1,-5.5$, $\mathrm{p}<0.001),-14.1 \mathrm{ml} / \mathrm{m}^{2}(95 \% \mathrm{CI}-21.9,-6.3 \mathrm{p}<0.001)$ and $13.0 \mathrm{ml} / \mathrm{m}^{2}(95 \% \mathrm{CI}-23.3,-2.6 \mathrm{P}<0.015)$ respectively, which were shown to be associated with airflow limitation in multivariate models. In the COPD group associations were found with lung hyperinflation (LVSVI: $\beta=-0.075, p=0.032$; Left atrial size: $\beta=-0.129, p=0.047$ ) and fibrinogen (TAC: $\beta=0.716$, $\mathrm{p}=0.030$ ).

Conclusion Surrogates for cardiovascular outcomes are adversely affected in COPD compared to a group matched for global cardiovascular risk, suggesting that current scoring systems may be suboptimal for cardiovascular risk prediction in COPD. 


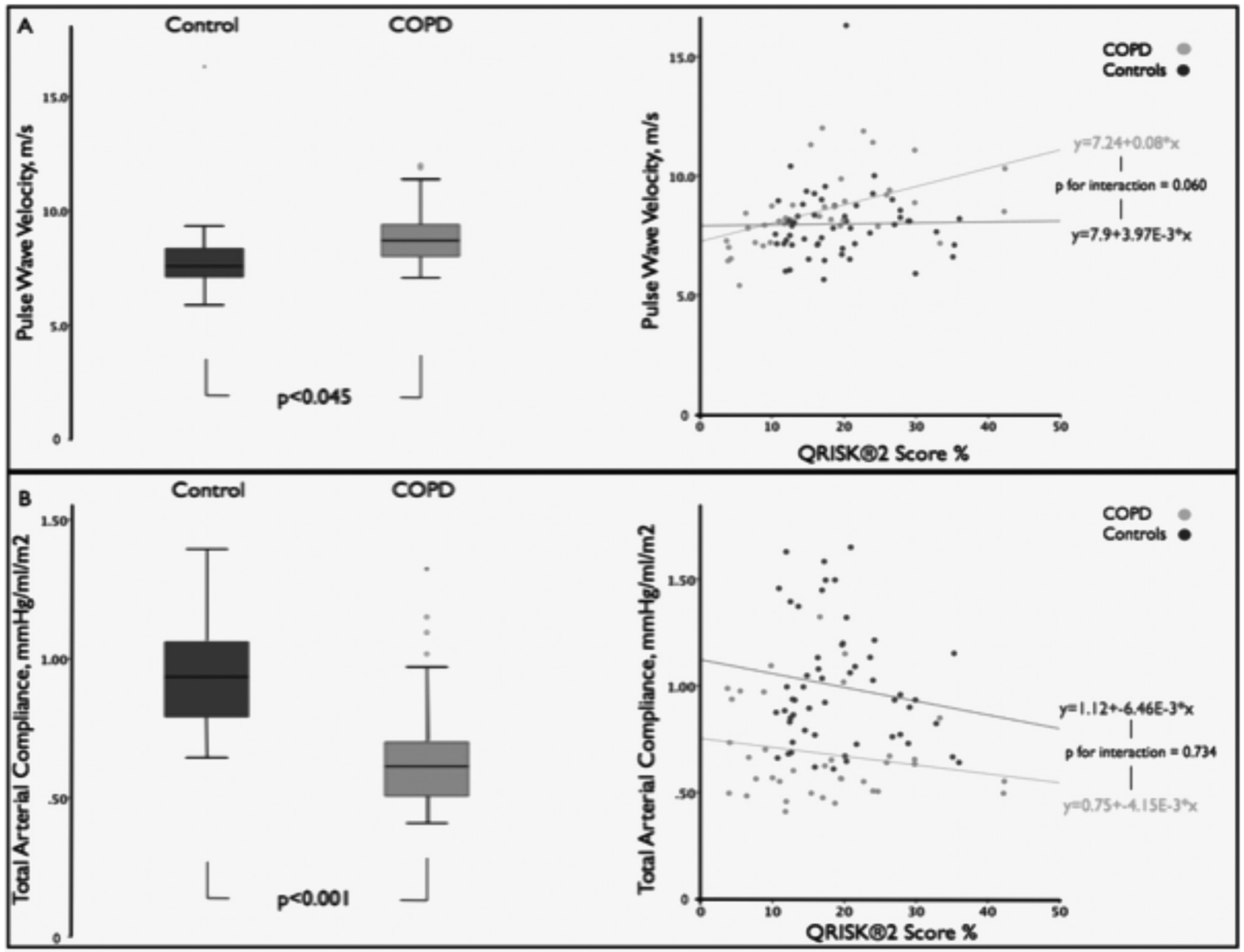

\section{Differences in pulse wave velocity, total arterial compliance and their relationship to QRISK®2 in COPD compared to controls matched for cardiovascular risk}

\section{Abstract P21 Figure 1}

\section{P22 DISTRIBUTION AND PREDICTION OF 10-YEARS RISK FOR CORONARY HEART DISEASE IN COPD}

${ }^{1}$ A Albarrati, ${ }^{2}$ NS Gale, ${ }^{2} \mathrm{M}$ Munnery, ${ }^{2} \mathrm{JR}$ Cockcroft, ${ }^{2} \mathrm{DJ}$ Shale. ${ }^{1}$ King Saud University, Riyadh, Saudi Arabia; ${ }^{2}$ Cardiorespiratory Medicine, Cardiff University, Cardiff, UK

\subsection{6/thoraxjnl-2015-207770.159}

Introduction Cardiovascular disease (CVD) is the leading cause of morbidity and mortality in COPD in excess of the effect of smoking. Clarification of cardiovascular risk factors could clarify the extra risk and lead to appropriate clinical management. We hypothesise that COPD increases the 10 year risk for CVD in patients free of clinically overt CVD.

Methods Using data from ARCADE study, 382 stable patients with COPD free from CVD and 143 controls were assessed for; lung function (forced expiratory volume $\left(\mathrm{FEV}_{1}\right)$, forced vital capacity (FVC) and their ratio), blood pressure (BP), BMI, aortic pulse wave velocity (PWV) and number of exacerbations. In addition, medical and smoking history were recorded and used to calculate the Framingham risk score (FRS). ${ }^{1}$
Results Patients with COPD had greater FRC, 24 (8) than controls, 19 (9), $\mathrm{p}<0.001$. The majority of patients were at high risk, $72 \%$, while only $7 \%$ were at low risk. There was no difference between genders. Post hoc analysis showed patients at high risk of CVD had greater aortic stiffness, $10.2(2.4) \mathrm{m} / \mathrm{s}$ compared to patients at low, 8.3 (2) $\mathrm{m} / \mathrm{s}$ and moderate risk, 9.1 (2) $\mathrm{m} / \mathrm{s}, \mathrm{p}<0.001$. The FRS was related to age, $\mathrm{r}=0.39, \mathrm{p}<$ 0.001 , waist circumference, $\mathrm{r}=0.11, \mathrm{p}=0.026$, and number of exacerbations, $\mathrm{r}=0.10, \mathrm{r}=0.039$, but was not related to $\mathrm{FEV}_{1}$.

Conclusion The majority of our patients were at high risk of developing fatal and non-fatal cardiovascular events. Early identification of cardiovascular risk factors and aggressive management would contribute to lowering the incidence of CVD in COPD.

\section{REFERENCE}

1 D'Agostino RB, Grundy S, Sullivan LM, et al. Validation of the Framingham coronary heart disease prediction scores: results of a multiple ethnic groups investigation. JAMA 2001;286:180-187 